\title{
O Medicamento, um Objeto de Futuro NA ANTRopologia da SAÚdE ${ }^{1}$
}

\section{Alice Desclaux ${ }^{2}$}

\section{Resumo}

0 medicamento - produto farmacêutico industrial - tornou-se um objeto central de estudo em antropologia médica no decurso dos dez últimos anos. 0 artigo passa em revista as condições históricas que conduziram os antropólogos, até então interessados pelos "remédios" provenientes dos saberes autóctones, a considerar os medicamentos. Depois de uma apresentação das abordagens teóricas, que são autoridade nesse assunto, discute-se a relação entre medicamento e cultura. São apresentados os estudos recentes referentes a cinco eixos temáticos: a polissemia e a "cadeia" dos medicamentos; as multiterapias antiretrovirais, pedido dos médicos e significações para os pacientes; os estudos em antropologia política e crítica dos sistemas terapêuticos, a dimensão "iatrogênica" dos medicamentos; a emergência dos medicamentos neotradicionais. São discutidas as perspectivas de pesquisa referentes, principalmente, ao domínio da produção científica e industrial dos medicamentos.

Palavras-chaves: medicamento, antropologia médica, revista, sistemas terapêuticos

\section{INTRODUÇão}

\section{O Medicamento no Centro da Antropologia Médica}

O $s$ medicamentos - que definiremos como produtos farmacêuticos industriais, elaborados com base em referências científicas da biologia, da biomedicina e da farmácia - estão, doravante, no centro das relações com a doença em quase todas as sociedades. São objetos particulares, pois estão saturados de significações e usos. Objetos concretos, às vezes prosaicos, integrados no espaço particular e no tempo

\footnotetext{
${ }^{1}$ Artigo recebido para publicação no original em francês : « Le médicament, un objet d'avenir en anthropologie de la santé ». Tradução para português pela Prof ${ }^{a}$. Rejane Jacqueline de Queiroz Fialho Tillefer, Universidade Estadual de Londrina.

${ }^{2}$ Professeur d'ant ${ }^{\text {th }}$ opologie, Université Paul Cézanne email: desclaux@mmsh.univ-aix.fr
} 
cotidiano, que parecem justificados por uma eficácia material sobre os corpos, escapando, em grande parte, da consciência daqueles que os consomem; objetos cuja materialidade é terrivelmente eficaz, já que centenas de milhões de pessoas devem sua (sobre)vida apenas à sua consumação. São igualmente o suporte de um investimento ideal, de interpretações, de elaborações simbólicas, em relação com a cultura científica biomédica que os produz e com as múltiplas culturas e subculturas que os (re)interpretam. São mais que objetos sociais, veiculando papéis, relações de saberes e de poderes mais ou menos desiguais, que legitimam a organização de instituições, sistemas, redes. Seu valor de troca fundamenta um sistema econômico e jurídico organizado, do microssocial ao plano internacional. Seu papel crucial no saber da biomedicina, na relação terapêutica e na relação do indivíduo com o corpo sadio ou enfermo deixaria pensar que foram objeto de numerosos estudos desde os inícios da antropologia médica. Isso não acontece em todos os lugares, como mostra uma revista internacional (SAILLANT e GENEST, 2006), principalmente no Brasil, onde o tema parece pouco abordado (LEIBING, 2006). Ademais, os trabalhos que se interessaram pelo assunto são bastante recentes no Brasil. Esse artigo também vai tentar fazer uma apresentação sintética das relações entre medicamentos e cultura(s) situando-os no campo da antropologia médica, depois de apresentar as aberturas temáticas recentes, para discutir enfim pistas de análise em torno desse rico objeto de estudo.

A relação entre culturas e medicamentos foi tratada de diversas maneiras durante os últimos trinta anos, período em que a antropologia médica conheceu importantes desenvolvimentos, tanto nos planos teórico e metodológico como empírico. Em alguns casos, o medicamento invadiu os estudos etnomedicais em diversos temas, demonstrando sua difusão progressiva em novos territórios geográficos ou sociais conforme os trabalhos arrolados por Benoist (2002). Várias correntes da antropologia médica interessaram-se pelo assunto de maneira mais sistemática, como: a etnofarmacologia, que estuda a construção cultural dos remédios em articulação com a análise farmacológica dos produtos utilizados; a antropologia política da saúde, que analisa os fatos de saúde e de enfermidade em termos de relações de poder econômico e político; a antropologia médica crítica, que aborda a biomedicina enquanto produção cultural; a etnopsiquiatria, que analisa as relações entre psiquismo, saúde mental e cultura, como faz a antropologia clínica. Certos trabalhos consideraram o medicamento como um objeto de estudo "clássico", que focaliza certas questões particularmente pertinentes, neste início de século, no campo da saúde pública ou no da antropologia médica; outros mostram que o medicamento coloca questões específicas. Em 2003, perguntava-se sobre o fato de que essa produção 
científica constitui um domínio temático da antropologia médica ou desenha uma nova corrente com sua ossatura teórica, seus objetos e métodos, justificando 0 qualitativo proposto por Van der Geest e Reynolds Whyte (1988) da « antropologia farmacêutica » (DESCLAUX e LÉVY). 0 debate é sempre atual e pode ser reavivado por uma produção científica importante dos últimos anos.

\section{Da Antropologia do Remédio à Antropologia do Medicamento}

Passemos em revista os fatores que favoreceram a multiplicação recente destes trabalhos e a constituição do medicamento como um objeto pertinente em antropologia. 0 interesse da antropologia pelo medicamento só seguiu com atraso o desenvolvimento e a extensão de seus usos. Até os anos 1980, a maioria das pesquisas consagradas às terapêuticas somente se interessavam pelos "remédios" sob suas formas mais diversas - das farmacopéias aos objetos terapêuticos. A partir dos anos 1960, as firmas farmacêuticas e os organismos científicos desenvolvem uma pesquisa em etnofarmacologia voltada para os saberes terapêuticos, na esperança de descobrir substâncias animais, minerais ou vegetais, nas propriedades farmacológicas suscetíveis de fornecer o substrato para o desenvolvimento de novos medicamentos. 0 papel do etnólogo era limitado ao estabelecimento de inventários de taxonomias, práticas de transformação ou de conservação das preparações terapêuticas "tradicionais", sem abordar os usos complementares de medicamentos (FLEURENTIN, PELT e MAZARS, 2002). Essas pesquisas desenvolveram-se sob o efeito da política da Organização Mundial da Saúde em matéria de atendimentos de saúde primária, expressa na declaração de Alma Ata, em 1978, que abria o caminho para a utilização das medicinas tradicionais nos sistemas de atendimento com a condição de que provassem sua eficácia. Assim, porque um "remédio" tal qual uma decocção ou um objeto terapêutico preparados segundo receitas rituais está, em sua primeira leitura, mais carregado de sentidos para o etnólogo do que um simples comprimido e porque a pesquisa em etnofarmacologia prometia tanto o aceso para todos os medicamentos simples e "naturais" previstos pela OMS como para os tesouros farmacológicos suscetíveis de serem explorados pelas firmas, o medicamento foi por muito tempo eclipsado na pesquisa antropológica em benefício do remédio.

A história do medicamento começou no século XVIII, quando se coloca um paradigma científico (articulado sobre uma teorização cada vez mais desenvolvida sobre os mecanismos de funcionamento do organismo e sobre as propriedades farmacológicas das substâncias químicas, naturais ou sintéticas) que contribui para a produção de 
tratamentos mais eficazes (CHAST, 1995; DAGOGNET, 1964). No século seguinte, principia a produção industrial de medicamentos a partir de técnicas de extração dos alcalóides vegetais (quinino, morfina, estricnina...) e de sua comercialização depois da fabricação sintética de compostos tendo propriedades farmacológicas reconhecidas e provenientes de produtos naturais (carvão, petróleo) ou sintéticos (benzina ou fenol, por exemplo). Na sequiência, os progressos na química dos colorantes sintéticos estarão na base de importantes inovações: os sulfamidas que permitiram lutar eficazmente contra as doenças infecciosas, os anti-histamínicos e os primeiros neurolépticos, como a cloropromazina, derivam desses trabalhos. Na origem do que se qualificou de "revolução terapêutica" do século XX (FAURE, 1999), está a produção dos primeiros antibióticos como a penicilina, depois, novas classes terapêuticas compreendendo os corticoides, a pílula contraceptiva, o fator de coagulação, os anti-hipertensores..., que revolucionarão as estratégias de tratamento cobrindo um espectro cada vez mais extenso de enfermidades. Por causa de suas recaídas econômicas muito importantes, os medicamentos são objeto de uma competição feroz, conduzida pelas grandes multinacionais farmacêuticas cujos métodos de pesquisa e técnicas de produção situamse nos confluentes de numerosas disciplinas (química, biologia, genética e robótica). $\mathrm{Na}$ vida cotidiana, os medicamentos ocupam um lugar essencial, demonstrado pela assimilação de nomes comerciais de medicamentos, tais quais Prozac $($ ou Viagra $®$, no vocabulário corrente de populações cada vez mais vastas nos cinco continentes. Os domínios da vida, transtornados pela eficácia material dos medicamentos, não concernem mais somente 0 tratamentos das doenças, mas a gestão da fecundidade, da nutrição ou das emoções... Entretanto, as três últimas décadas colocaram outra vez em questão os sucessos dos medicamentos, essencialmente pelos seguintes motivos: a aparição de limites na eficácia de tratamentos, tais quais: os antibióticos confrontados com a emergência de resistências bacterianas; a frequiência crescente de efeitos tóxicos geradores de patologias iatrogênicas ocupando doravante um lugar importante nas causas de mortalidade; as desigualdades sociais no acesso aos tratamentos doravante conhecidas pelo público; a visibilidade das estratégias das firmas dominadas pelas lógicas de lucro. Os antiretrovirais que, prescritos em multiterapias, transformaram o prognóstico da infecção pelo HIV, cristalizaram as questões de saúde pública referentes aos medicamentos, particularmente em torno da iniqüidade de sistemas de atendimentos incapazes de assegurar 0 acesso às inovações terapêuticas para todos aqueles cuja sobrevida depende disso. Essa história do medicamento, marcada pelos sucessos e fracassos de um ponto de vista de saúde pública, é também uma história social, política e cultural. 
É notável que a antropologia do medicamento tenha emergido em um período de "desencantamento" face à terapêutica farmacêutica, como se os limites da eficácia abrissem um espaço de reflexão até então ocultado por uma abordagem positivista. É em torno da utilização dos medicamentos nos países do sul, simultaneamente a partir de interrogações aplicadas e em uma perspectiva de antropologia social e cultural, que Van der Geest e Reynolds Whyte (1988), primeiros líderes deste campo de pesquisa, realizaram ou coordenaram os primeiros trabalhos conseqüentes em antropologia do medicamento seguidos, depois, por outros pesquisadores, frequentemente associados à Unidade de Antropologia Médica da Universidade de Amsterdã (ETKIN e TAN, 1994; TAN, 1989; HARDON, 1987). Depois, o retorno para uma « anthropology at home » conduziu pesquisadores a se interessarem pelo medicamento nos países desenvolvidos, enquanto objeto transcedendo os espaços do individual ao social, do privado ao público, do sanitário ao religioso e, simultaneamente, operador técnico e simbólico no centro da relação terapêutica (AKRICH, 1995; BENOIST, 1999; FAINZANG, 2001). Os trabalhos sobre a construção social das patologias mentais nas sociedades ocidentais abordaram o medicamento como produto aditivo, como "marcador social" ou como terapêutica (EHRENBERG e LOVELL, 2002, HAXAIRE, 2002)3. Finalmente, desdobraram-se pesquisas concernentes a outras classes terapêuticas, relativas a patologias diversas.

\section{Abordagens Téoricas em Antropologia do Medicamento}

Os cartões de leitura antropológica do medicamento disponíveis constituem um princípio de ossatura teórica comum para novos trabalhos. Ao se fundamentar em um corpus importante de estudos etnográficos, Nichter e Vuckovic (1994) propuseram uma agenda de pesquisa sobre a antropologia dos usos dos medicamentos, envolvendo seus principais riscos a partir da exposição de dez temas maiores cobrindo ao mesmo tempo os níveis micro e macrossocial, dos aspectos ideológicos até as conseqüências do uso dos medicamentos sobre as modalidades de atendimentos de primeira linha. Em 1996, Van der Geest, Whyte e Hardon publicam um inventário das pesquisas em antropologia do medicamento a partir de uma "perspectiva biográfica" que ordena os trabalhos segundo uma cronologia, desde as fases de produção dos medicamentos até a avaliação de sua eficácia e, isto, levando em conta contextos, atores e formas de transações que estão associadas a cada etapa. 0 valor heurístico dessa abordagem, desenvolvida na

\footnotetext{
${ }^{3}$ Nesse campo, como em outros, é impossível citar todos os trabalhos realizados: nossa escolha volta-se para as publicações mais ilustrativas de uma corrente e para aquelas que oferecem uma reflexão teórica ou uma apresentação sintética de trabalhos.
} 
obra de síntese (WHYTE, VAN DER GEEST e HARDON, 2002), foi demonstrado pelo fato de que ela foi freqüentemente utilizada para definir e contextualizar estudos monográficos voltados para uma ou outra das "etapas biográficas": produção, marketing, difusão, receita, distribuição; utilização; eficácia dos medicamentos.

Os trabalhos de Jean Benoist, que se interessou pela construção da eficácia social dos medicamentos nos sistemas médicos, recorrem a um outro modelo que distingue, em círculos concêntricos imbricados, as relações pessoais do indivíduo com o medicamento, o nível microssocial da inscrição do medicamento em uma relação terapêutica e em uma relação com "outros significantes" pertencendo ao meio, o nível mesossocial dos grupos, categorias e redes sociais e o nível macrossocial da "sociedade", estreitamente articulado com a escala nacional do sistema de atendimento, ele próprio inscrito em um nível "mundial" (1999). A análise das interações entre diferentes níveis desse sistema permite considerar, principalmente, as variações do sentido do medicamento em um contexto de pluralismo médico (BENOIST, 1996).

Os estudos que se voltaram para a difusão e a distribuição dos medicamentos mostram quanto esses dois aspectos inscrevem-se simultaneamente nas lógicas econômicas e políticas complexas, regidas por contextos jurídicos localmente diversos, em curso de modificação no quadro da regulamentação da Organização Mundial do Comércio. Nessa análise, o modelo de Kleinman (1980), que descreve um sistema médico composto de três setores de atendimentos de saúde (popular, biomédico e tradicional) revela-se muito útil para apreender a implicação dos atores. Com a condição de ser adaptado às configurações locais, esse modelo teórico permite mostrar como os medicamentos circulam em e entre esses três setores permeáveis, quando das transferências entre mercados formais e informais, que apelam para empreendedores múltiplos (distribuidores, atacadistas, médicos, farmacêuticos, comerciantes, vendedores não qualificados), contribuindo com a difusão dos medicamentos nesses espaços variados, em constante competição e expansão. Essa circulação de produtos é acompanhada de uma circulação de significações e discursos sobre o sentido dos medicamentos (KAMAT e NICHTER 1998; OKUMURA, WAKAI e UWENAÏ, 2002). 0 conceito de "sistema do medicamento" (corolário do conceito antropológico de "sistema médico", no sentido de sistema de significações, sistema social e sistema operatório) permite analisar as configurações locais.

A distinção, que constitui um dos paradigmas da antropologia médica, entre illness - que corresponde a "doença significada", tal qual ela é percebida e interpretada pelo doente -, disease - que corresponde à realidade biológica dos distúrbios -, e sickness - que corresponde à doença socializada -, fornece igualmente uma ferramenta 
de análise pertinente. Ao adaptar esse conceito à análise das variações locais da relação entre o "medicamento significado e interpretado pelo paciente", o medicamento definido por seus efeitos biológicos e o "medicamento socializado", pode-se abordar questões relativas ao vivido pelos tratamentos, às percepções de sua eficácia e de seus efeitos secundários, às lógicas subjacentes à automedicação, à subconsumação ou à superconsumação médica, às reinterpretações da receita.

Finalmente, as dimensões sociais e culturais de um medicamento só podem ser compreendidas se ele estiver situado na farmacopéia e entre outras terapêuticas disponíveis localmente, que constituem um sistema dinâmico. Dagognet (1964) qualifica esse sistema de "pharmacocénose », em eco ao conceito de pathocénose ${ }^{4}$, considerando que cada elemento terapêutico qualificado por suas características materiais e ideais está em inter-relações com outros medicamentos e remédios na ocupação de um espaço terapêutico. A pertinência dessa abordagem é mostrada, principalmente, na monografia de Tan (Filipinas. 1989), sobre um "sistema do medicamento".

\section{Medicamentos e Cultura}

0 papel da cultura na determinação das significações, dos usos e das instituições, construídos em torno dos medicamentos, é uma questão central. Mais freqüentemente tomado no que se pode considerar como uma relação intercultural, oriunda de uma cultura biomédica que o saturou de sentidos, o medicamento é interpretado ou reinterpretado em diversas culturas locais ou subculturas populares e profissionais. Como a antropologia médica, a antropologia do medicamento sofreu então a interferência da problemática do culturalismo em saúde pública (FASSIN, 2002): OS estudos realizados em torno dos tratamentos antiretrovirais mostraram que, contrariamente aos discursos das instituições sanitárias, no Haiti ou na África, os pacientes não observam as recomendações por causa dos esquemas cognitivos ou por causa de uma relação com o medicamento, próprios de "sua cultura", mas por causa de suas práticas e, portanto, à eficácia dos tratamentos. Os pacientes dependem,

\footnotetext{
${ }^{4} \mathrm{NT}$ - nosso grifo. 0 termo francês designa "o estado de equilibrio das doenças em um determinado momento da história e em determinada sociedade. Assim, a presença e a importânc ${ }^{\text {ja }}$ de uma doença em uma determinada população e em determinada época dependem da presença e da importância das outras doenças. A idéia diretriz é, portanto, o fato de que as doenças são interdependentes. Com este conceito, Grmek quis facilitar a abordagem da história das doenças e melhorar a compreensão das doenças emergentes. Esta n ${ }^{\circ}$ ão é desenvolvida, principalmente, em sua "História da Aids", onde ele adianta que a descoberta da penicilina e da antibioterapia fizeram desaparecer, progressivamente, as doenças bacterianas, permitindo a emergência de doenças virais até então laten"es." (Disponível em http://fr.wikipedia.org/wiki/Pathoc\%C3\%A9nose. Acesso em 08/01/07).
} 
primeiramente, da organização das instituições sanitárias e dos aspectos econômicos que determinam o acesso a medicamento (FARMER, 2001; LANIÈCE, 2003). A cultura não está ausente, mas esses trabalhos mostram que ela deve ser abordada, em primeiro lugar, sob o ângulo econômico ou político, e considerando as inter-relações entre a inserção do medicamento na cultura das instituições sanitárias e nas culturas locais. Pode-se igualmente perguntar-se sobre os elementos culturais que determinam a relação individual com o medicamento. Além dos aspectos examinados pela etnomedicina, da etnofisiologia à etnofarmacologia, os usos do medicamento parecem abrir uma "janela" sobre dimensões fundamentais da cultura tais quais: a relação com o saber, a noção de ordem ou a de autoridade, cuja predeterminação, no espaço íntimo, pela aculturação com uma religião é examinada por Fainzang (2001). A análise pode igualmente voltarse para as mudanças culturais induzidas pelo medicamento bem além do espaço de atendimento: como lembram Van der Geest e Reynolds Whyte (2003), o medicamento suscita transformações da relação com o corpo e da norma entre saúde e bem estar. 0 alcance dessas mudanças culturais e o papel que o medicamento aí representa-operador ou revelador - devem ainda ser documentados em numerosos contextos.

Trabalhos cada vez mais numerosos mostram que os medicamentos inscrevem-se nos sistemas de sentidos ou de relações sociais dinâmicas (NICHTER e VUCKOVIC, 1994, HAXAIRE, 2003, DESCLAUX, 2003). Um aumento de volume de « sistemas » parece, aliás, disponível para análise, sob o risco de afastar a reflexão, incluindo a noção de "sistema do medicamento", proveniente da antropologia e já mencionada, que se interessa pelos setores biomédico, tradicional e popular articulando níveis de análise concernente ao social e ao simbólico; a noção de "sistema farmacêutico", transposição da noção de sistema de atendimento proveniente da saúde pública, articulando os setores público, particular e informal. As interfaces entre setores foram freqüentemente objetos de estudos, tais quais, por exemplo, o artigo pioneiro que descreveu a emergência do novo papel social dos "injection doctors", entre os setores popular e profissional, entre os setores público e informal (CUNNINGHAM, 1970). 0 escoamento ${ }^{5}$ rápido dos medicamentos e a freqüência da colocação no mercado de moléculas, que suscitam permanentemente uma renovação do campo terapêutico, permitem observar as dinâmicas desses sistemas, principalmente em termos de se por no lugar mecanismos de controle dos saberes associados e do acesso aos produtos, de re-interpretações e redesdobramentos dos produtos e remédios pré-existentes, de construção de novas legitimidades sociais ou de renegociações das legitimidades anteriores. Isso equivale a dizer que o estudo do

${ }^{5} \mathrm{NT}$ - em francês, o termo está grafado em inglês - turn-over. 
medicamento é uma porta de entrada para os sistemas terapêuticos. Em uma perspectiva sincrônica, os modelos evocados acima oferecem também uma ferramenta de análise comparativa muito pertinente, ainda pouco utilizada para confrontar sistemas relativos a diversos produtos ou diversos sites.

\section{Temáticas Recentes em Antropologia do Medicamento}

Como se vê, os conceitos que foram utilizados para abordar a relação entre medicamentos e culturas são essencialmente oriundos da antropologia médica e se inscrevem nas abordagens contemporâneas da antropologia social e cultural. Citemos, não obstante, cinco grandes temas recentemente explorados, que só poderão ser apresentados aqui de modo sumário.

\section{Polissemia e “Cadeia dos Medicamentos"}

Van der Geest e Reynolds Whyte (2003) mostram quanto um mesmo produto pode ser popular e objeto de ceticismo, carregado de significações múltiplas por diferentes atores, em inter-relações consensuais ou conflituosas. A polissemia do medicamento é alimentada pelo seu percurso biográfico, que está acompanhado por um cortejo de valores evolutivos e pela sua difusão em diversos espaços sociais e culturais - do íntimo do corpo individual ao mundializado das instituições internacionais. Ela é também devida a certa ambivalência material: os medicamentos são, ao mesmo tempo, cura e veneno, seus efeitos biológicos nunca são totalmente benéficos nem anódinos. Eles impõem aos indivíduos, terapeutas e pacientes, fazer escolhas que estão freqüentemente baseadas em representações marcadas ora pela ideologia, ora pela construção cultural do corpo, ora pela forma de percepção induzida pelo desejo de eficácia - que alimenta o efeito placebo (ETKIN, 2004, SOW, 2004, HAXAIRE, 2003, MOERMAN, 2002). Essa polissemia é, sem dúvida, um conceito indispensável para abordar os riscos de saúde pública ligados ao medicamento nas sociedades contemporâneas, tais quais: a superconsumação medicamentosa ou a automedicação denunciadas pelas instituições sanitárias.

É nessa perspectiva que numerosos estudos documentaram os usos e significações dos medicamentos nos países desenvolvidos voltando-se principalmente para as representações, tentando explicar sua reconstrução em diversos contextos como é 0 caso do programa de pesquisa canadense "a cadeia dos medicamentos" (COLLIN, 2003; DUFORT e SAUVAIRE, 2006). No Brasil, Nery Filhio [sic] e colaboradores exploraram a composição das farmácias familiares na Bahia e mostraram a importância significativa 
de certas classes terapêuticas e o lugar doravante muito limitado que aí ocupam os tratamentos medicinais populares, ainda muito presentes em estudos anteriores realizados na zona rural ou em outras cidades (2006).

\section{As Multiterapias Antiretrovirais: Pedido dos Médicos e Significações para os Pacientes}

Durante os últimos dez anos, o desenvolvimento dos tratamentos antiretrovirais suscitou uma produção importante de estudos primeiramente realizados a pedido da medicina. Tendo a particularidade de serem constrangedores e de necessitar, para serem eficazes, de taxas de observância muito elevadas, esses tratamentos foram primeiramente solicitados aos antropólogos para explicitar as dimensões sociais e culturais que condicionam a observância e o vivido pelo tratamento (WRIGHT, 2000; SOUTEYRAND e MORIN, 2001). Os estudos dedicaram-se a determinar a problemática em um quadro conceitual pertinente para as ciências sociais, principalmente ao distinguir a noção "de adesão" que remete às representações que os pacientes têm pelo interesse dos tratamentos e a noção "de observância" que remete às práticas de tomar os medicamentos (ABELHAUSER, 1998; DESCLAUX, 2001). Os estudos realizados nos países desenvolvidos mostraram as reorganizações que as pessoas sob antiretrovirais devem efetuar em sua vida de todos os dias para gerar a temporalidade desses tratamentos de longa duração e as significações estigmatizadas que lhes são associadas (LÉVY, PIERRET e TROTTIER, 2004). A "socialização" dos tratamentos fora da esfera médica, na esfera doméstica, no mundo do trabalho e nas redes associativas foi analisada para compreender os embaraços que regem a comunicação em torno do tratamento. A preservação do segredo conduz, às vezes, os indivíduos a modificar as suas redes de sociabilidade para se aproximar de outras pessoas que têm preocupações similares, o que as conduz a fazer escolhas determinantes para sua experiência da doença crônica (WALLACH, 2006). Esse "vivido" do tratamento foi explorado nas populações de origens culturais variadas, que vivem em diversos contextos (marginalidade, uso de tóxicos, precariedade social...) ou situações face ao HIV (gravidez, doença sintomática, co-infecção AIDS - tuberculose...). Essas análises contribuem para a reflexão sobre as variações e traços comuns na experiência da doença, abrindo a via para estudos referentes a outras patologias. Essa antropologia interpretativa permite questionar a oposição simplista entre "saúde" e "doença", em um período em que as doenças crônicas, que podem ser consideradas como um estado de "saúde sob tratamento", tomam um lugar que se expande na paisagem epidemiológica. 


\section{Os Estudos em Antropologia Política e Crítica dos Sistemas Terapêuticos}

Em contextos de recursos limitados, as primeiras tentativas de tratamento por antiretrovirais foram objeto de análises, adotando o ponto de vista da antropologia aplicada, articulando um estudo crítico das condições macrossociais do acesso aos tratamentos e uma avaliação da responsabilidade sanitária. Por um lado, o objetivo era melhorar as práticcas de atendimento adaptando-as às situações locais; de outro lado, mostrar a possibilidade do tratamento em um período em que os especialistas internacionais eram reticentes à utilização dos antiretrovirais nos países pobres tais quais: Haiti, Costa do Marfim e Senegal (FARMER et al., 2001, MSELLATI et al., 2001, DESCLAUX et al., 2004). Esses trabalhos também explicaram as condições sociais da equiidade no acesso aos atendimentos, descreveram as desigualdades e processos de categorizações que produzem a vulnerabilidade de certas populações face aos serviços de atendimento, reduzindo suas capacidades de acesso aos tratamentos ou de observância. À medida que os programas do tratamento da AIDS generalizaram-se em numerosos países, os antropólogos orientaram-se novamente para a análise crítica das políticas de saúde pública, tanto em matéria de profilaxia antiretroviral (por exemplo, para a prevenção da transmissão do HIV mãe-filho) como em matéria de terapêutica ${ }^{6}$. Sobre esses temas, a análise científica alimenta a tentativa de saúde pública e o engajamento militante em favor do acesso aos atendimentos: é certo que os trabalhos citados mais acima ou a Pétition Free x 5 em favor da gratuidade dos tratamentos da AIDS para os pacientes (WHITESIDE e LEE, 2005) inspiraram ou desviaram as políticas internacionais, principalmente as estratégias da iniciativa $3 \times 5 \mathrm{da}$ OMS, que se tornou Universal Access em 2006, visando generalizar o acesso aos tratamentos nos países em desenvolvimento. Os estudos críticos dos sistemas de atendimento no plano nacional ou local permitiram compreender os obstáculos estruturais ou conjunturais na eficácia dos tratamentos, particularmente no caso da AIDS e da tuberculose (SINGER e CASTR0, 2004, FARMER e CASTRO, 2003, BOURDIER, 2004, NGUYEN, 2005). Eles contribuem igualmente para uma antropologia dos valores subjacentes às políticas de saúde.

\section{A Dimensão “Iatrogênica” dos Medicamentos}

A abordagem que, em epistemologia ou em antropologia, interessa-se pela

\footnotetext{
${ }^{6}$ Certo número de estudos foi apresentado em um quadro de uma rede internacional "Antropologia dos antiretrovirais em países com recursos limitados » (NAARPS : Network on the Anthropology of Pharmaceuticals in Resource-Poor Settings), coordenado pelo CReCSS (Centro de Pesquisa Culturas, Saúde, Sociedades da Universidade Paul Cézanne d'Aix-Marseille, França) e a Unidade de Antropologia Médica da Universidade de Amsterdã: www.mmsh.univ-aix.fr/crecss/naarps
} 
construção social das categorias nosológicas, produziu análises muito interessantes sobre a maneira pela qual a difusão de medicamentos faz emergir "novas" patologias. Nesse caso, a cura precede o mal e ela condiciona 0 aspecto, a existência social e a percepção daqueles que sofrem desse mal: a existência de um tratamento medicamentoso conduz a medicar as variações de humor ou aspectos da vida biológica, tais qual a menopausa ou a síndrome pré-menstrual; a transformar simples fatores de risco, tais qual a osteoporose ou a hipercolesterolemia em patologias; a transformar problemas de saúde anódinos em patologias graves. Nas sociedades em que a legitimidade do medicinal é enorme, ao ponto de se tornar norma utilizar qualquer terapia medicamentosa disponível, a indústria farmacêutica não éo único ator dessa construção social. Distúrbios como a síndrome das pernas sem repouso (WOLOSHIN e SCHWARTZ, 2006), os distúrbios de ereção (LEXCHIN, 2006), a disfunção sexual feminina (TIEFER, 2006) estão popularizados pelas mídias e são aumentados perto dos médicos pelo uso de avaliações exageradas de sua prioridade, o que tem como efeito corroborar uma receita e uma automedicação. A análise pertence a uma antropologia política preocupada em decifrar as lógicas dos atores e as tramas de interesses e responde a uma exigência de saúde pública (MINTZES, 2006). Ela pode assim ser interpretativa quando se volta para a redefinição das normas emocionais e afetivas quando tratamentos "reguladores do humor" ou outros psicotrópicos estão amplamente disponíveis (PIGNARRE, 2001; MEDAWAR e HARDON, 2004). Assim, além dos efeitos indesejáveis dos medicamentos que ocasionam patologias iatrogênicas caracterizadas, suficientemente propaladas e graves para representar um problema de saúde pública maior, os medicamentos criariam, por mecanismos sociais e culturais, um deslocamento da fronteira entre o normal e 0 patológico, entre o que é tolerável e o que precisa de atendimento.

\section{A Emergência dos Medicamentos "Neotradicionais"}

Durante muito tempo, os tratamentos foram distribuídos de ambos os lados de uma linha de partilha entre remédios (compostos majoritariamente de plantas medicinais) e medicamentos, pertencentes aos saberes autóctones e biomédicos, sustentados, por um lado, pelos tradipráticos locais e, de outro, pelos comunicadores formados em biomedicina. Diversas formas de sincretismo médico desenvolveram-se durante as últimas décadas, apoiando-se, principalmente, na movimentação dos terapeutas, na democratização do acesso às novas tecnologias e aos conceitos científicos e em um movimento de identidade que valoriza simultaneamente as "tradições" locais e usa um discurso científico cosmopolita para legitimar suas propostas terapêuticas. 
Isso se traduz pelo surgimento de medicamentos "neotradicionais" que são registrados por seus promotores como complemento ou alternativa aos tratamentos biomédicos, reinterpretando todos em seu proveito terá eficácia associada a esses últimos (DESCLAUX, 2003; SIMON, 2004). Que sejam provenientes de saberes empíricos locais fragmentários, associados aos sistemas médicos tradicionais tal qual o Ayurveda, ou presos a uma tradição descrita por seus promotores como partilhada entre as grandes civilizações, esses produtos combinam freqüentemente uma fabricação industrial, uma apresentação similar àquela dos medicamentos do circuito farmacêutico oficial, uma legitimação por ensaios clínicos e um discurso que sublinha sua autenticidade, evocando freqüentemente a noção de "panacéia". Apoiando-se sobre redes de difusão parcialmente específicas, desprezando freqüentemente quadros jurídicos, a distribuição desses produtos utiliza redes próprias nos países em desenvolvimento, o mercado informal que acolhe igualmente produtos contrafeitos e os laboratórios onde o controle dos medicamentos é sumário. Nos países desenvolvidos, esses produtos, difundidos pelas farmácias de dietéticos ou farmácias e "para-farmácias" são freqüentemente vendidos como complementos nutricionais ou estéticos, ou como produtos "anti-idade", conforme uma categorização que tenta impor-se no campo da medicina. Esses produtos podem ser objetos de vários níveis de análise: eles confirmam reapropriações do discurso ou tentativa científica pelos diversos mundos sociais; testemunham a porosidade das interfaces entre setores lícito e ilícito (TAVERNE, 2001) e a extensão da circulação dos medicamentos, apesar dos limites colocados pelo quadro jurídico e dos acordos comerciais internacionais; eles permitem ver um aspecto particular da "reinvenção da tradição", demonstrando uma forma de mundialização "por baixo", escapando dos sistemas de controle e dos organismos internacionais.

\section{Perspectivas}

As pesquisas evocadas acima mostram a que ponto podem ser confundidas a experiência íntima dos tratamentos no momento de sua consumação pelos indivíduos e as dimensões macroeconômicas, políticas e científicas de sua legitimação e sua produção no outro extremo da "cadeia dos medicamentos". As primeiras etapas da "biografia do medicamento", incluindo as relações de poder entre firmas, poderes públicos, associações e médicos, foram examinadas a respeito dos tratamentos antiretrovirais (DALGALARRANDO, 2004, EPSTEIN, 1996). De modo mais geral, a fase da produção científica e industrial e o papel que aí representam não somente a indústria farmacêutica, mas todos os setores sociais envolvidos é um domínio que foi esclarecido pelas análises pertencentes às ciências políticas (PIGNARRE, 2003), econômicas 
(MOATTI, 2005) ou jurídicas (CASSIER e CORRÉA, 2006), mas ainda muito pouco explorado pela antropologia. É certo que a escolha da abordagem é particularmente difícil, de um lado, pela tentação de uma leitura puramente crítica, amplamente justificada em um campo em que as lógicas macroeconômicas prevalecem sobre a ética e, de outro, pelas dificuldades de acesso aos dados em terrenos muito protegidos. No entanto, além das leituras maniqueístas, foram abertas pistas que consideram que a produção farmacêutica é um dos lugares em que as sociedades devem tratar dilemas complexos e carregados de riscos culturais e sociais maiores, relativos principalmente à gestão do futuro e do risco ou à definição do bem-estar (URFALINO, 2005; PETRYNA, LAKOFF e KLEINMAN, 2006). Nesses campos, falta elaborar as abordagens que associam a antropologia, a economia e as ciências políticas.

$\mathrm{Na}$ outra extremidade da "cadeia", os temas de análises puramente interpretativas, centradas no "experimentado" individual, são numerosos, pois as declinações em torno da enorme quantidade dos produtos pertencendo a todas as classes terapêuticas, experimentados pelas diversas populações e situações sociais, poderiam justificar um número infinito de estudos. 0 desafio é então pressentir objetos particularmente significativos socialmente ou simbolicamente e, talvez, encontrar novas formas de exploração ou de restituição do vivido pelos tratamentos, sendo que os métodos clássicos de antropologia não são sempre muito atuantes em torno dessas questões.

Essa apresentação pretende apenas ilustrar algumas das múltiplas perspectivas de pesquisa pertinentes no Brasil ou alhures.

\section{Conclusões}

Este breve panorama forçosamente redutor mostra que o medicamento constitui um tema central, na encruzilhada dos questionamentos contemporâneos sobre a mundialização, a saúde e os sistemas terapêuticos. Revelador privilegiado dos riscos sócio-políticos e culturais, ele permite compreender, de modo original, as transformações nestes campos que atingem, ao mesmo tempo, os sistemas sócio-culturais e os indivíduos em sua relação com o corpo, suas práticas de saúde e suas interpretações da doença e da cura. A contribuição que a antropologia brasileira poderá trazer para a análise destas questões será amplamente apreciada, particularmente porque os esforços dos atores do sistema de atendimento brasileiro em favor de em acesso igualitário aos medicamentos são reconhecidos no plano internacional e os efeitos sociais e culturais desta política não foram totalmente descritos. 


\section{RÉFÉRENCES}

ABELHAUSER, Alain, « Observance, compliance or adherence? Social impact and psychic mechanisms ». Paris, ANRS, Le sida en Europe, 1998, non paginé.

AKRICH, Madeleine, «Petite anthropologie du médicament », Revue Techniques et culture, n²5-26, 1995, p. 129-157

BENOIST, Jean, « À propos du rapport entre dimension technique et médiation symbolique dans le médicament", in 0. Faure (ed), Les thérapeutiques : savoirs et usages. Lyon, Collection Fondation Marcel Mérieux, 1999, p. 383-394

BENOIST, Jean (dir), Soigner au pluriel, Essais sur le pluralisme médical. Paris, Karthala, 1996 BENOIST, Jean, Petite bibliothèque d'anthropologie médicale. Une anthologie. Paris, Karthala, AMADES, 2002

BOURDIER, Frédéric, Migration et sida en Amazonie française et brésilienne, Ibis rouge, 2004 CASSIER, Maurice, CORREA Marilena, « Propriété intellectuelle et santé publique : la copie des antirétroviraux contre le VIH/sida dans les laboratoires brésiliens ", in DUFORT, Francine, SAIVES, Anne-Laure (eds), Le médicament : conception, production et consommation: perspectives interdisciplinaires pour un avenir commun, GEIRSO, 2005, p. 133-146

CASTRO, Arachu, FARMER, Paul, «Violence structurelle, mondialisation et tuberculose multirésistante », Antbropologie et sociétés, 2003, 27, 2, p. 23-40

CHAST, François, Histoire contemporaine des médicaments. Paris, Éditions La Découverte, 1995

COLLIN, Johanne, « Médicament et vieillissement. Trois cas de figure », Anthropologie et sociétés, 2003, 27, 2, p. 119-138

CUNNINGHAM C., «Thai "Injection Doctors", antibiotic medicators », Social Science and Medicine 4, 1970, p. 1-24

DAGOGNET, François, La raison et les remèdes, Paris, PUF, 1964

DALGALARRANDO, Sébastien, 2004, Sida : la course aux molécules. Paris, Editions de l'EHESS

DESCLAUX, Alice, « Les antirétroviraux en Afrique. De la culture dans une économie mondialisée », Anthropologie et sociétés, 2003, 27, 2, p. 41-58

DESCLAUX, Alice, "Equity in access to AIDS Treatment in Africa : pitfalls amongst achievements » in Singer M., Castro A. (eds), Unhealthy bealth policy : a critical medical anthropology perspective. Lanham, Altamira Press, 2004, p. 115-132

DESCLAUX, Alice, LANIECE Isabelle, NDOYE, Ibra, TAVERNE, Bernard (eds), The Senegalese Antiretroviral Drug Access Initiative, An Economic, Social, Bebavioural and Biomedical Analysis. Paris, ANRS, UNAIDS, WHO 
DESCLAUX, Alice, LEVY, Joseph J. « Cultures et médicaments. Ancien objet ou nouveau courant en anthropologie médicale ? » Antbropologie et sociétés, 2003, 27, 2, p. 5-22

DUFORT, Francine, SAIVES, Anne-Laure (eds), « Le médicament : conception, production et consommation : perspectives interdisciplinaires pour un avenir commun ». ${ }^{\text {er }}$ congrès international interdisciplinaire sur la Chaîne du Médicament. Théories et pratiques, 30 août - 2 septembre 2005, Montréal, GEIRSO

EHRENBERG, Alain, LOVELL Anne (eds), La maladie mentale en mutation. Psychiatrie et société. Paris, Odile Jacob, 2001

EPSTEIN, Steven, Impure science. AIDS, activism and the politics of knowledge, Los Angeles, University of California Press, 1996

ETKIN, Nina L., « The Negotiation of 'Side' Effects in Hausa (Northern Nigeria) Therapeutics » in N.L. Etkin et M.L. Tan (dirs), Medicines: Meanings and Contexts, Amsterdam et Quezon City, The Philippines: University of Amsterdam et HAIN, 1994, p. 17-32

FAINZANG, Sylvie, Médicaments et sociétés. Le patient, le médecin et l'ordonnance. Paris, PUF, 2001

FARMER, Paul, LEANDRE F, MUKHERJEE JS, CLAUDE MS et al. « Community-based approaches to HIV treatment in resource-poor settings » The Lancet, 2001: 358, p. 404-409

FASSIN, Didier, « Le culturalisme pratique de la santé publique. Critique d'un sens commun » in Dozon, J.P., Fassin D. (eds), Critique de la santépublique. Une approche anthropologique. Paris: Balland, 2001, p.181-207

FAURE, Olivier (ed), Les thérapeutiques : savoirs et usages. Lyon, Fondation Mérieux, 1999

FLEURENTIN, Jacques, PELT, Jean-Marie, MAZARS, Guy (eds), Des sources du savoir aux médicaments du futur, Paris, IRD, 2002

HARDON Anita, «The use of modern pharmaceuticals in a Filipino Village : doctor's perception and self-medication ", Social Science \& Medicine, 25, 1987, p. 277-292.

HAXAIRE Claudie, " "Calmer les nerfs" : automédication, observance et dépendance aux médicaments psychotropes ». Sciences sociales et santé, 20, 1, 2002, p. 63-88

HAXAIRE Claudie, «Toupaille », kits MST et remèdes du « mal d'enfants » chez les Gouro de Zuénoula (Côte d'Ivoire) », Anthropologie et sociétés, 2003, 27, 2, p. 77-98

KAMAT, V.R. et M. NICHTER, « Pharmacies, self medication and pharmaceutical marketing in Bombay, India », Social Science \& Medicine, 47(6) 1998, p. 779-794.

KLEINMAN Arthur, Patients and healers in the context of culture, Berkeley, university of California Press, 1980

LANIECE, Isabelle, CISS, Mounirou, DESCLAUX, Alice, DIOP Karim, MBODJ Fatou, NDIAYE, Balima, SYLLA, Omar, DELAPORTE, Eric, NDOYE, Ibrahim, « Adherence to HAART and its principal determinants in a cohort of Senegalese adults ».AIDS, vol 7 [Suppl 3, p. S103-S108] 
LEIBING, Annette, " De l'anthropologie médicale, et bien plus... Le corps sain et l'identité brésilienne », in Saillant, Francine, Genest, Serge (eds), Anthropologie médicale. Ancrages globaux, défis locaux. Paris, Economica, Anthropos, 2006, p. 113-131.

LEVY Joseph J., PIERRET Janine, TROTTIER Germain (eds), Les traitements antirétroviraux : expériences et défis, Montréal, Presses de l'Université du Québec, 2004

LEXCHIN Joel, « Bigger and better: how Pfizer redefined erectile dysfunction » PLOS Medicine, 3, 4, 2006, p. 1-4: www.plosmedicine.org

MEDAWAR Charles, HARDON Anita, Medicines out of control ? Antidepressants and the conspiracy of goodwill. Aksant, 2004

MINTZES Barbara, « Disease mongering in drug promotion: do governments have a regulatory role? » PLOS Medicine, 3, 4, 2006, p. 1-5: www.plosmedicine.org

MOERMAN, Daniel, Meaning, medicine and the placebo effect, Cambridge University Press, 2002 MSELLATI, Philippe, VIDAL, Laurent, MOATTI, Jean-Paul (eds), L'accès aux traitements du VIH/ sida en Côte-d'foire : Aspects économiques, sociaux et comportementaux. Paris, ANRS, 2001

NERY FILHIO, Antonio, DA ROCHA, Junior Mario Augusto, SILVA, Lima Gilberto Inacio, ALVES DE ALMEIDA, Sampaio Junior, MASCARENHAS Ramos Paulus Fabricio, VIANA, Baroso Ana Carolina, FAMED, LEVY Joseph J., « La pharmacie domestique au Brésil : distribution des classes de médicaments », in DUFORT, Francine, SAIVES, Anne-Laure (eds), Le médicament : conception, production et consommation : perspectives interdisciplinaires pour un avenir commun. GEIRSO, 2005, 561-572

NGUYEN Vin Kim, The republic of iherapy: Biopolitics before and after HIV in West Africa and beyond. Durham, Duke University Press, 2005

NICHTER, Mark, VUCKOVIC, Nancy, Agenda for an anthropology of pharmaceutical practices, Social Science \& Medicine, 39 (11), 1994, p. 1509-1525.

OKUMURA, J., WAKAI S., UMENAI, T., « Drug utilization and self-medication in rural communities in Vietnam», Social Science \& Medicine, 54, 2002, p.1875-1886.

PETRYNA Adriana, LAKOFF Andrew, KLEINMAN Arthur (eds), Global pharmaceuticals. Ethics, Markets, Practices, Duke University Press, 2006

PIGNARRE, Philippe, Comment la dépression est devenue une épidémie. Paris, La Découverte, 2001

PIGNARRE, Philippe, Le grand secret de l'industrie pharmaceutique. Paris, La Découverte, 2003 REYNOLDS WHYTE, Susan, VAN DER GEEST Sjaak, HARDON, Anita (eds.), Social lives of medicines, Cambridge University Press, 2002

SAILLANT, Francine, GENEST, Serge (eds), Anthropologie médicale. Ancrages globaux, défis locaux. Paris, Economica, Anthropos, 2006. 
SIMON, Emmanuelle, 2004, Les initiatives de promotion des thérapeutiques traditionnelles au Bénin, nouveanx enjeux thérapeutiques, politiques et religieux, thèse d'anthropologie, Université de Montpellier III, UFR V Sciences du sujet et de la société : 533 p.

SINGER, Merrill, CASTRO, Arachu (eds), Unhealthy bealth policy : a critical medical anthropology perspective. Lanham, Altamira Press, 2004

SOUTEYRAND, Yves, MORIN, Michel (eds), L'observance aux traitements du VIH/sida : mesure, déterminants, évolution. Paris, ANRS, 2001

SOW, Khoudia, DESCLAUX, Alice, « Antiretroviral treatment adherence and its determinants: a qualitative analysis », in DESCLAUX, Alice, LANIECE Isabelle, NDOYE, Ibra, TAVERNE, Bernard (eds), The Senegalese Antiretroviral Drug Access Initiative, An Economic, Social, Behavioural and Biomedical Analysis. ANRS, UNAIDS, WHO, 2004, p. 101-108

TAN, Michel L., Good medicine: pharmaceuticals and the construction of power and knowledge in the Philippines. Amsterdam: Her Spinhuis, 1989

TAVERNE, Bernard, "Enjeux individuels et collectifs autour de la circulation des antirétroviraux », Transcriptase Sud, 6, 2001, p. 32-36

TIEFER, Leonore, «Female sexual dysfunction: a case study of disease mongering and activist resistance » PLOS Medicine, 3, 4, 2006, p. 1-5: www.plosmedicine.org

VAN DER GEEST, Sjaak, REYNOLDS WHYTE, Susan, HARDON, Anita, « The anthropology of pharmaceuticals: A biographical approach ». Annual Review of Anthropology 25, 1996, p.153-78.

VAN DER GEEST, Sjaak, REYNOLDS WHYTE, Susan (eds.), The Context of Medicines in Developing Countries: Studies in Pharmaceutical Anthropology. Dordrecht, Kluwer, 1988

VAN DER GEEST, Sjaak, REYNOLDS WHYTE, Susan, «Popularité et scepticisme : opinions contrastées sur les médicaments ", Anthropologie et sociétés, 27, 2, 2003, p. 97-118

WALLACH, Isabelle, L'observance aux médicaments contre le VHH/sida. Thèse d'ethnologie, Université de Paris VII, 23 octobre 2006, 629 p.

WHITESIDE, Alan, LEE, Sabrina, « The "Free by 5 " Campaign for universal, free antiretroviral therapy ». PLOS Medicine, 2, 8, 2005, p. 101-104, www.plosmedicine.org

WOLOSHIN, Steven, SCHWARTZ, Lisa M., « Giving legs to restless legs: a case study of how the media helps make people sick » PLOS Medicine, 3, 4, 2006, p. 452-456: www.plosmedicine.org WRIGHT, M.T., The old problem of adherence: research on treatment adherence and its relevance for HIV/AIDS. AIDS Care, 12, 6, 2000, p. 703-710

URFALINO, Philippe, Le grand méchant loup pharmaceutique, Textuel, 2005 